\begin{tabular}{|c|c|c|}
\hline 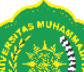 & NERACA & Seric \\
\hline & $\begin{array}{l}\text { JURNAL PENDIDIKAN EKONOIMI } \\
\text { http://journal.umpalanqkaraya.ac.id/index.php/neraca }\end{array}$ & 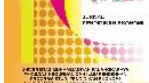 \\
\hline UMP & Volume 6 Nomor 1, November $2020(30-36)$ & $2 \times 5 x^{5}$ \\
\hline
\end{tabular}

\title{
MELALUI PENERAPAN METODE PEMBELAJARAN INSIDE OUTSIDE CIRCLE GUNA MENINGKATKAN PRESTASI BELAJAR IPS MATERI PROKLAMASI KEIMERDEKAAN INDONESIA PADA SISWA KELAS V B SD NEGERI 1 BATU BADINDING \\ Through The Implementation Of The Inside Outside Circle Learning Method To Improve The Achievement Of Ips Material Learning Proclamation Of Indonesian Independence In Grade V B Students Of SD Negeri 1 Batu Badinding Yelita \\ SD Negeri I Batu Badinding, Katingan, Kalimantan Tengah, Indonesia
}

\section{ARTIKEL INFO}

Diterima

September 2020

Dipublikasi

November 2020

*e-mail :

rikuatno spd@yahoo.co.id
ABSTRAK

Proses pembelajaran Ilmu Pengetahuan Sosial (IPS) kelas V B dengan Pokok Bahasan Proklamasi kemerdekaan Indonesia, setelah diadakan evaluasi pada kondisi awal diperoleh hasil yang tidak memuaskan dimana sebanyak 9 siswa atau 34,62\% tidak tuntas karena di bawah Kriteria Ketuntasan Minimal (KKM) yaitu 75. Sedangkan yang mempunyai nilai di atas KKM sebanyak 17 siswa atau 65,38\%. Untuk itu diadakan perbaikan pembelajaran dengan menggunakan metode Inside Outside Circle. Hasil siklus I adalah sebanyak 22 siswa atau $84,62 \%$ tuntas, sedangkan 4 siswa atau 15,38\% siswa tidak tuntas. $\mathrm{Hal}$ ini berarti ada peningkatan terhadap ketuntasan belajar siswa. Tingkat ketuntasan ini sudah di atas $85 \%$. Tetapi rata-rata prestasi belajar $(79,15)$ masih berada di bawah rata-rata sesuai indikator keberhasilan yaitu 75, maka diadakan lagi perbaikan pembelajaran dengan siklus II. Hasil yang dicapai pada siklus II adalah sebanyak 24 siswa atau 92,31\% tuntas dan 2 siswa atau 7,69\% tidak tuntas. Hal ini berarti ada peningkatan terhadap ketuntasan belajar siswa. Ketuntasan $92,31 \%$ yang berada di atas $85 \%$ ini menandakan bahwa perbaikan pembelajaran pada siklus II dengan menggunakan metode Inside Outside Circle telah berhasil.

Kata kunci: Metode Pembelajaran Inside Outside Circle, Pembelajaran IPS, Materi Proklamasi Kemerdekaan Indonesia

\section{ABSTRACT}

The learning process of Social Sciences (IPS) class VB with the Subject of the Proclamation of Indonesian independence, after an evaluation was held in the initial conditions, unsatisfactory results were obtained where 9 students or $34.62 \%$ were incomplete because under the Minimum Completeness Criteria (KKM), namely 75 Meanwhile, 17 students or $65.38 \%$ had scores above the KKM. For this reason, learning improvements were made using the Inside Outside Circle method. The results of the first cycle were as many as 22 students or $84.62 \%$ completed, while 4 students or $15.38 \%$ students did not complete. This means that there is an increase in student learning completeness. This level of completeness is already above $85 \%$. But the average learning achievement (79.15) is still below the average according to the success indicator, which is 75 , so learning improvements are held again with cycle II. The results achieved in the second cycle were as many as 24 students or $92.31 \%$ completed and 2 students or $7.69 \%$ incomplete. This means that there is an increase in student learning completeness. $92.31 \%$ completeness which is above $85 \%$ indicates that the learning improvement in cycle II using the Inside Outside Circle method has been successful.

Keywords: Inside Outside Circle Learning Method, Social Studies Learning, Material of the Proclamation of Indonesian Independence 


\section{PENDAHULUAN}

Pembelajaran merupakan sebuah proses yang dialami oleh peserta didik. Peserta didik yaiotu anak-anak tidak akan lepas dari nilai dan karakter anak. Diamnapun dia berada, pola tingkah laku dan kebiasaan selalu mengacu pada nilai anak. Dalam pembelajaran, guru cenderung menstadarkan apa yang dilakukan anak harus sesuai dengan pola piker guru sebagai orang dewasa. Dan fatalnya, bentuk hukuman salah satu bentuk penerapan disiplin agar anak mengikuti guru. Inilah yang sering kali didapati dalam sebuah pembelajaran di dalam kelas. Anak menjadi malas dan kurang bergairah dalam belajara, rasa was-awas jika kritis, jika sedikit ramai, kelas yang lengang dan tegang menjadikan anak tidak menikmati porses belajarnya di sekolah.

Salah satu bentuk pembelajaran yang bias diterapkan adalah metode inside outside circle. Dalam metode Inside Outside Circle termasuk salah satu metode pembelajaran koperatif (cooperative learning) dimana pengelompokan menjadi unsur utamanya. Diketahui, bahwa pola pengelompokan haruslah ditata secara benar dan tepat. Tata pengelompokan ini bisa pada kuantitas masing-masing kelompok, bisa pula pada durasi waktu perubahan anggota dalam masing-masing kelompok.

Berlatar belakang dari permasalahan yang terjadi di atas, peneliti mencoba untuk melakukan Penelitian eksperimen dengan menerapkan strategi Inside Outside Circle. Strategi pembelajaran ini membantu siswa dalam mengkonstruksi pengetahuannya sendiri sehingga pemahaman konsep siswa menjadi lebih baik.

\section{Metode Inside Outside Circle}

Sebagaimana telah dijelaskan di awal bab, bahwa dalam rangka memaksimalkan diterimanya suatu pengetahuan kepada anak didik (siswa), maka diperlukan suatu cara, langkah, atau juga seni dalam menyampaikan pelajaran. Seni menyampaikan pelajaran/pengetahuan dalam pendidikan ini biasa disebut dengan seni mengajar. Karena dalam mengajar membutuhkan seni, maka keterampilan dan keahlian seperti berbicara, dan atau menggunakan segala media untuk menyampaikan pengetahuan mutlak diperlukan. Dalam ilmu pendidikan, apa yang disebut dengan seni dan cara mengajar/mendidik ini biasa disebut dengan metode atau juga model belajar-mengajar yang di dalamnya memuat tentang teknik mengajar, tujuan, dan manfaat strategis yang didapatkan. Apa yang diinginkan dari teknik pembelajaran ini sebenarnya tidak jauh dari upaya mengembangkan potensi siswa.

Dalam konsep kompetensi yang kemudian melahirkan Kurikulum Berbasis Kompetensi (KBK) beberapa tahun lalu, kita menemukan rumusan konseptual kompetensi, yaitu, untuk meningkatkan:

a. Pengetahuan (konowledge);

b. Pengertian (understanding);

c. Keterampilan (skills);

d. Nilai (value); dan

e. minat (interest).

Lima muatan pengajaran dengan konsep kompetensi ini dimaksudkan untuk mengembangkan tiga potensi pendidikan di dalam diri manusia, yaitu: kognitif, afektif, dan psikomotorik.

Dari titik pandang di ataslah metode pembelajaran penting adanya, termasuk metode inside outside circle. Dan agar lebih terfokus dan terarah, maka penulis jelaskan tentang metode inside outside circle yang secara sistematis sebagai berikut:

a. Pengertian metode inside outside circle Agar lebih rinci, maka di sini perlu pula diketahui pengertian dua kata kunci, yaitu metode dan inside outside circle.

I) Metode

Dalam pengertiannya, apa yang disebut metode adalah cara yang di dalam fungsinya 
Jurnal Pendidikan Ekonomi

merupakan alat atau media untuk mencapai suatu tujuan. Hal ini berlaku bagi guru (metode mengajar) maupun kepada murid/siswa (metode belajar). Karena metode merupakan cara yang dalam pendidikan bertujuan untuk tercapainya tujuan pembelajaran, maka semakin baik metode mengajar yang dipakai guru dan metode belajar yang diterapkan kepada murid, maka semakin efektif suatu usaha mencapai tujuantujuan pendidikan.

2) Inside outside circle

Secara umum, apa yang dimaksud dengan metode inside outside circle (IOC) adalah mode pembelajaran dengan sistim lingkaran kecil dan lingkaran besar (Spencer Kagan, 1993), di mana siswa saling membagi informasi pada saat yang bersamaan dengan pasangan yang berbeda dengan singkat dan teratur. Sintaksnya adalah: Separuh dari jumlah siswa membentuk lingkaran kecil menghadap keluar, separuhnya lagi membentuk lingkaran besar menghadap ke dalam, siswa yang berhadapan berbagi informasi secara bersamaan, siswa yang berada di lingkarn luar berputar kemudian berbagi informasi kepada temn (baru) di depannya, dan seterusnya.

b. Tujuan metode inside outside circle

Dalam setiap kegiatan belajar, tidak terlepas dari suatu tujuan yang hendak dicapai. Pada dasarnya, pencapaian tujuan pendidikan ditentukan oleh kemampuan guru, karena faktor pendidik sangat besar peranannya. Sekiranya pendidik itu baik, maka hasil pendidikannya akan lebih baik pula.

Maka kemudian dikenallah yang namanya pengajaran koperatif (cooperative learning). Konsep inti daripada cooperative learning adalah menempatkan pengetahuan yang dipunyai siswa merupakan hasil daripada aktivitas yang dilakukannya, bukan pengajaran yang diterima secara pasif.

\section{Pembelajaran IPS}

Pengertian IPS menurut Departemen Pendidikan dan KebudayaanRepublik Indonesiadalam Soewarso (2013: I) ialah bidang studi yang merupakan gabungan dari beberapa mata pelajaran, sedangkan menurut Nasution menyatakan bahwa IPS merupakan suatu program pendidikan yang pada pokoknya mempersoalkan hubungan manusia dalam lingkungan fisik maupun dalam lingkungan sosialnya, dan yang diambil dari berbagai ilmu-ilmu sosial: geografi, sejarah, ekonomi, antropologi, sosiologi, politik dan psikologi sosial.

IPS merupakan mata pelajaran yang mempelajari tentang telaah manusia dan dunianya, seperti yang dikemukakan oleh Soewarso (2013: 5) bahwa "hakikat IPS adalah telaah tentang manusia dan dunianya". IPS melihat manusia dari berbagai sudut pandang. IPS melihat bagaimana manusia hidup bersama sesamanya di lingkungan sendiri, dengan tetangganya, yang dekat sampai yang jauh. IPS merupakan kajian yang luas tentang manusia dan dunianya, sehingga dapat menimbulkan kesulitan pada mereka yang menggelutinya.

\section{Materi Pembelajaran Ilmu Pengetahuan Sosial (IPS) Proklamasi kemerdekaan Indonesia}

Jasa dan peran tokoh di sekitar proklamasi kemerdekaan

Menceritakan Peristiwa-Peristiwa

Penting yang Terjadi di Sekitar Proklamasi Dalam bulan Agustus 1945, terjadi beberapa peristiwa penting, terutama menjelang pelaksanaan proklamasi Kemerdekaan RI di Jakarta.

I. Peristiwa Rengasdengklok

Pada malam hari, tanggal I5 Agustus 1945, para tokoh pemuda mengadakan rapat kilat . keputusan rapat adalah segera memproklamasikan kemerdekaan Indonesia pada tanggal 16 agustus 1945. Sebab, Jepang sudah kalah, dan sekutu belum datang. Pada 
Jurnal Pendidikan Ekonomi

tanggal 16 Agustus 1945, tiga tokoh pemuda terdiri atas Sukarni, Yusuf Kunto, dan singgih membawa Bung Karno dan Bung hatta ke Rengasdengklok , Jawa Barat. Di Rengasdengklok, para pemuda mendesak Bung Karno dan Bung Hatta agar segera melaksanakan proklamasi Kemerdekan Indonesia. Pada sore hari tanggal 16 Agustus 1945 , Mr Ahmad Soebarjo datang untuk menengahi pertentangn pendapat antara pemuda dengan Bung Karno dan Bung Hatta tersebut. Setelah melakukan musyawarah, dan akhirnya mereka memutuskan untuk memproklamasikan kemerdekaan Indonesia pada tanggal 17 Agustus 1945.

2. Penyusunan Teks Proklamasi

Tanggal 17 Agustus 1945 pukul 04.00 WIB dini hari, Bung Karno, Bung Hatta dan Mr.Achmad Subarjo berhasil menyusn naskah proklamasi .Yang kemudin diketik oleh Sayuti Melik.

\section{METODE PENELITIAN}

Penelitian ini dilaksanakan di SD Negeri I Batu Badinding . Kelas yang diteliti adalah kelas $\mathrm{V} B$ dengan jumlah siswa 26 orang. Pemilihan tempat ini didasarkan pada pertimbangan:

I. Peneliti mengajar mata pelajaran IImu Pengetahuan Sosial (IPS) kelas $\vee \mathrm{B}$ di SD Negeri I Batu Badinding Tahun Pelajaran 2017/20I8.

2. Adanya permasalahan terhadap prestasi belajar yang rendah dalam pembelajaran Ilmu Pengetahuan Sosial (IPS) pada konsep Proklamasi kemerdekaan Indonesia.

Penelitian ini berlangsung selama tiga bulan pada semester genap yaitu mulai dilaksanakan bulan Maret sampai dengan bulan Mei 2018 . Rincian kegiatan penelitian tersebut adalah sebagai berikut:

I. Persiapan penelitian;

2. Koordinasi persiapan tindakan;
3. Pelaksanaan (perencanaan tindakan, pelaksanaan tindakan, monitoring dan evaluasi, dan refleksi).

4. Penyusunan laporan penelitian

Subjek penelitian ini adalah siswa dan guru Ilmu Pengetahuan Sosial (IPS) SD Negeri I Batu Badinding . Siswa yang dijadikan subjek penelitian ini adalah siswa kelas $\vee B$. Dengan perkataan lain, kelas $\mathrm{V} B$ ditetapkan sebagai setting kelas. Sementara itu guru yang dijadikan subjek penelitian adalah peneliti sendiri dengan dibantu dengan teman sejawat selaku observer yang juga guru bidang studi Ilmu Pengetahuan Sosial (IPS).

Data penelitian yang dikumpulkan berupa informasi tentang prestasi belajar siswa dalam pelajaran Ilmu Pengetahuan Sosial (IPS) pada konsep Proklamasi kemerdekaan Indonesia, serta kemampuan guru dalam menyusun rencana pembelajaran dan melaksanakan pembelajaran (termasuk penggunaan strategi pembelajaran) di kelas. Data penelitian itu dikumpulkan dari berbagai sumber yaitu informasi atau nara sumber, yaitu siswa dan guru / teman sejawat dan Dokumen atau arsip, yang antara lain berupa Kurikulum, Rencana Pelaksanaan Pembelajaran, hasil evaluasi siswa, dan buku penilaian.

Adapun teknik pengumpulan data yang digunakan dalam penelitian ini adalah observasi dan dokumentasi. Observasi, yaitu pengamatan terhadap subyek penelitian, dimana penulis mencatatnya dalam lembar observasi hasil pengamatan tersebut. Dokumentasi, yaitu pengumpulan data berupa catatan-catatan mengenai pokok-pokok permasalahan yang diteliti, seperti: data siswa dan daftar nilai siswa.

Alat pengumpulan data dalam metode penelitian ini adalah lembar observasi, pedoman wawancara dan daftar nilai siswa.

Proses untuk meningkatkan pemahaman terhadap konsep Proklamasi kemerdekaan Indonesia pada pelajaran IImu 
Pengetahuan Sosial (IPS) yang diterapkan pada siswa dengan menggunakan metode observasi, dokumentasi dan wawancara divalidasi datanya melalui Triangulasi Data.

Teknik analisis data yang digunakan adalah teknik deskriptif komparatif dan teknik analisis kritis. Teknik deskriptif komparatif digunakan untuk membandingkan hasil antar siklus yaitu prestasi belajar siswa pada konsep Proklamasi kemerdekaan Indonesia sebelum siklus, siklus I dan siklus II. Sedangkan teknik analisis kritis untuk menganalisis hasil observasi dari teman sejawat dan wawancara dengan siswa yang telah terkumpul. Langkahlangkahnya yaitu dengan mengumpulkan data yang diperoleh, mengidentifikasikan, mengklarifikasikan, menghubungkan dengan teori literatur yang mendukung masalah kemudian menarik kesimpulan berdasarkan penelitian tindakan kelas yang telah dilakukan.

\section{HASIL PENELITIAN PEMBAHASAN}

I. Pra Siklus

Kriteria Ketuntasan Minimal (KKM) pada mata pelajaran Ilmu Pengetahuan Sosial (IPS) Pokok Bahasan Proklamasi kemerdekaan Indonesia adalah 75 . Siswa yang belum memenuhi KKM $(<75)$ adalah sebanyak 9 siswa atau $34,62 \%$ sedangkan yang sudah memenuhi KKM (>75) adalah sebanyak 14 siswa atau $65,38 \%$. Dengan demikian tingkat ketuntasan siswa masih kurang dari $85 \%$ sehingga memerlukan tindakan perbaikan pembelajaran agar tingkat ketuntasan siswa dalam pokok bahasan Proklamasi kemerdekaan Indonesia dapat meningkat. Nilai terendah yang diperoleh siswa adalah 35 dan nilai tertinggi adalah 80 .

Pada masa pra siklus nilai rata-rata adalah 70,08 . Siswa yang mempunyai nilai di bawah KKM (75) sebanyak 9 siswa atau $34,62 \%$ dan yang mencapai KKM sebanyak 17 siswa atau 65,38\%. Dengan demikian kondisi awal pada prestasi belajar siwa adalah rendah dimana rata-rata nilai siswa 70,08 masih kurang dari 75 dan tingkat nilai dibawah KKM masih tinggi $(65,38 \%)$.

\section{Siklus I}

Pada Siklus I terjadi peningkatan prestasi belajar IImu Pengetahuan Sosial (IPS) pokok bahasan Proklamasi kemerdekaan Indonesia. Dimana sebelum perbaikan ratarata yang dicapai adalah 70,08 meningkat menjadi 79,15. Kriteria Ketuntasan Minimal pada pelajaran Ilmu Pengetahuan Sosial (IPS) Pokok Bahasan Proklamasi kemerdekaan Indonesia adalah 75. Siswa yang belum memenuhi KKM $(<75)$ adalah 4 siswa atau $15,38 \%$ sedangkan yang sudah memenuhi KKM (>75) adalah 22 siswa atau 84,62\%.

Berdasarkan perbaikan Siklus I terjadi peningkatan hasil belajar, dimana pada Pra Siklus yang tidak memenuhi KKM sebanyak 9 siswa pada Siklus I berkurang menjadi 4 siswa. Kriteria Ketuntasan Minimal sudah melampaui indikator perbaikan pembelajaran $85 \%$ yaitu sebesar $84,62 \%$. Tetapi rata-rata nilai evaluasi masih di bawah 75 yaitu 79, 15 sehingga Siklus I dianggap gagal. Kegagalan ini dikarenakan dalam menggunakan metode Inside Outside Circle guru belum melibatkan siswa untuk aktif secara maksimal. Untuk menyikapi hal ini, maka peneliti mengadakan perbaikan pembelajaran Siklus II agar pembelajaran IImu Pengetahuan Sosial (IPS) pada Pokok Bahasan Proklamasi kemerdekaan Indonesia dapat memenuhi KKM yang ditetapkan.

Pada siklus I, siswa yang mempunyai nilai di bawah KKM sebanyak 7 atau 15,38\% sedangkan yang sudah memenuhi KKM (>75) adalah 22 siswa atau $84,62 \%$ melebihi indikator keberhasilan yaitu $85 \%$. Tetapi nilai rata-rata yang diperoleh yaitu 79,I5 dimana masih kurang dari rata-rata 75 . Untuk itu maka diadakan kembali perbaikan pembelajaran Siklus II.

\section{Siklus II}

Pada Siklus II ini hasil prestasi belajar terdapat 2 siswa atau 7,69\% yang mendapat 
nilai di bawah KKM yang ditetapkan yaitu 75 sedangkan 24 siswa atau 92,31\% siswa telah memenuhi KKM. Karena pada Siklus II ini tingkat ketuntasan siswa melebihi indikator kinerja yang ditetapkan yaitu $85 \%$, dan ratarata yang diperoleh 79,15 melebihi rata-rata 75 maka perbaikan pembelajaran Siklus II dinyatakan berhasil.

Pada siklus II nilai rata-rata yang diperoleh yaitu 79,15 melebihi rata-rata 75 . Siswa yang telah mencapai KKM sebanyak 24 siswa atau $92,31 \%$ sehingga telah melebihi indikator keberhasilan yang ditetapkan, sehingga pada siklus II perbaikan pembelajaran dinyatakan berhasil.

\section{KESIMPULAN}

Berdasarkan hasil pengolahan data dari perbaikan pembelajaran yang telah dilaksanakan dapat ditarik kesimpulan penggunaan metode Inside Outside Circle dengan melibatkan siswa secara aktif dalam pembelajaran Ilmu Pengetahuan Sosial (IPS) pada Pokok Bahasan Proklamasi kemerdekaan Indonesia sangat efektif untuk memudahkan siswa dalam memahami materi. Hasil penelitian pada kondisi awal diperoleh hasil yang tidak memuaskan dimana sebanyak 9 siswa atau $34,62 \%$ tidak tuntas karena di bawah Kriteria Ketuntasan Minimal (KKM) yaitu 75. Sedangkan yang mencapai KKM sebanyak 17 siswa atau 65,38\%. Rata-rata prestasi belajar Ilmu Pengetahuan Sosial (IPS) juga rendah yaitu 70,08 masih kurang dari rata-rata 75 . Siklus I, sebanyak 17 siswa atau $84,62 \%$ tuntas, sedangkan 4 siswa atau $15,38 \%$ siswa tidak tuntas. Tingkat ketuntasan ini sudah di atas $85 \%$. Tetapi rata-rata prestasi belajar yang dicapai 79,I5 masih berada di bawah rata-rata sesuai indikator keberhasilan yaitu 75 , maka diadakan lagi perbaikan pembelajaran dengan siklus II. Siklus II, sebanyak 24 siswa atau $92,31 \%$ tuntas dan 2 siswa atau $7,69 \%$ tidak tuntas. Rata-rata prestasi belajar IImu Pengetahuan Sosial (IPS) yaitu 79,15 berada di atas dari rata-rata 75. dengan hasil ini perbaikan pembelajaran pada siklus II dengan menggunakan metode Inside Outside Circle telah berhasil.

Berdasarkan hasil Penelitian Tindakan Kelas, terdapat beberapa hal yang sebaiknya dilakukan oleh guru untuk meningkatkan kualitas pembelajaran dan meningkatkan penguasaan Pokok Bahasan pelajaran Ilmu Pengetahuan Sosial (IPS) kepada siswa agar memperoleh hasil yang memuaskan adalah metode Inside Outside Circle guru perlu melibatkan siswa secara aktif dalam proses pembelajaran, misalnya memberikan kesempatan kepada anak untuk bertanya, berpendapat, dan Inside Outside Circle hasil pekerjaan di papan tulis. Perlu digunakan metode yang bervariasi sesuai dengan Pokok Bahasan pelajaran. Penggunaan metode yang monoton, misalnya metode ceramah saja secara terus menerus akan membuat siswa jenuh dan tidak memperhatikan pelajaran. Guru perlu memahami tingkat intelektualitas siswanya. Dalam pembelajaran Ilmu Pengetahuan Sosial (IPS) diperlukan metode yang tepat agar siswa tertarik untuk belajar Ilmu Pengetahuan Sosial (IPS). Misalnya penggunaan metode Inside Outside Circle divariasikan dengan metode yang lain seperti tanya jawab, permainan, diskusi, dll.

\section{DAFTAR PUSTAKA}

Ahmadi, Abu dan Uhbiyati, Nur. 1991. Ilmu Pendidikan. Cet. Ke-I. Jakarta: PT. Rineka Cipta.

Arikunto, Suharsimi. 2005. Manajemen Penelitian. Jakarta: PT. Asdi Mahasatya.

Djamarah, Syaiful Bahri dan Zaini, Aswan. 1996. Strategi Belajar-Mengajar. Jakarta: PT. Rineka Cipta.

Djamarah, Syaiful Bahri. 2005. Guru dan Anak Didik Dalam Interaksi Edukatif. Cet. Ke3. Jakarta: PT. Rineka Cipta.

Hadi, Sutrisno. 1994. Metodologi Researh: untuk Penulisan Paper, Tesis dan 
Jurnal Pendidikan Ekonomi

Disertasi. Cet. Ke-2I. Yogyakarta: Andi Offset.

Hamalik, Oemar. 2008. Kurikulum dan Pembelajaran. Cet. Ke-8. Jakarta: PT. Bumi Aksara.

2003. Proses Belajar Mengajar.

Cet. Ke-2. Jakarta: PT. Bumi Aksara. 1999. Pengembangan Kurikulum dan Pembelajaran: Dasar dan

Strategi Pelaksanaannya di Perguruan Tinggi. Bandung: PT. Trigenda Karya. Isjoni. 2009. Cooperative Learning: Efektifitas Pembelajaran Kelompok. Cet. Ke-2. Bandung: Alfabeta.

Iskandar, Sali. 1990. Pengantar Praktis Kewirausahaan. Bandung: Al Ghifari.

Ivos K Davis. 199I. Pengelolaan Belajar. Jakarta: CV. Rajawali Pers.

Jailani, Muhammad. 2018. Upaya Meningkatkan Hasil Belajar IPS Dengan Menerapkan Model Role Playing Berbantuan Media Papan Flanel Pada Peserta Didik Kelas IV-C SDN-I Sabaru Palangkaraya Tahun Pelajaran 2016/2017. Pedagogik: Jurnal Pendidikan I3(I):24-30.

Jusuf, Haryono Al. 200I. Dasar-dasar Akuntansi jilid I. Edisi 5. Yogyakarta: STIE YKPN.

Lie, Anita. 2008. Cooperative Learning: Mempraktikkan Cooperative Learning Di Ruang-ruang Kelas. Cet. Ke-6. Jakarta: Grasindo.

Majid, Abdul dan Andayani, Dian. 2005. Ilmu Pengetahuan Sosial (IPS) Berbasis Kompetensi. Cet. Ke-2. Bandung: PT. Remaja Rosda Karya.

Nasution. 2006. Berbagai Pendekatan Dalam Proses Belajar-Mengajar. Cet. Ke-I0. Jakarta: Bumi Aksara.

Pidarta, Made. 1997. Landasan Pendidikan. Cet. Ke-I. Jakarta: PT. Rineka Cipta. Salim, Peter dan Salim, Yenny. 199I.
Kamus Bahasa Indonesia Kontemporer. Jakarta : Modern English Press.

Setiawan, M Andi dan Diplan. 2018. Penelitian Tindakan Kelas. Yogyakarta: Deepublish.

Setyawan, Dedy dan Melda Arumi. 2015. Meningkatkan Hasil Belajar Matematika Dengan Menggunakan Metode Pembelajaran Role Playing Pada Peserta Didik Kelas 2 SDN-I Pahandut Palangka Raya. Tunas: Jurnal Pendidikan Guru Sekolah Dasar I(I):62-67.

Soekanto, Soerjono. 1986. Pengantar Penelitian Hukum. Jakarta: UI Press. Sudjana, Nana. 1995. Penilaian Hasil Proses Belajar Mengajar. Bandung: PT. Remaja Rosda Karya.

Surakhmad, Winarno. 1994. Pengantar Ilmu Dasar Metode dan Teknik. Bandung: CV. Tarsito.

Tafsir, Ahmad. 1996. Metodologi Pengajaran IImu Pengetahuan Sosial (IPS). Bandung: Remaja Rosda Karya.

Trianto. 2007. Model-model Pembelajaran Inovatif Berorientasi Konstruktivistik. Jakarta: Prestasi Pustaka.

Usman, Moh. Uzer dan Setiawati, Lilis. 1993. Upaya Optimalisasi Kegiatan BelajarMengajar. Bandung: PT. Remaja Rosda Karya.

Zuchdi, Darmiyati. Strategi Meningkatkan Kemampuan Membaca,.

Zuhairini. 2004. Pendidikan Berparadigma Profetik. Cet. Ke-I. Jogjakarta: Ircisod 